\title{
Effect of artesunate and relation with TGF- $\beta 1$ and SMAD3 signaling on experimental hypertrophic scar model in rabbit ear
}

\author{
Xiaolin Nong ${ }^{1}\left(\mathbb{1} \cdot\right.$ Girju Rajbanshi ${ }^{1,2} \cdot$ Ling Chen $^{1} \cdot$ Jiaquan $\mathrm{Li}^{3} \cdot$ Zhan $\mathrm{Li}^{1} \cdot$ Taotao Liu $^{4} \cdot$ Shihai Chen $^{5} \cdot$ Gao Wei $^{6}$. \\ Jushang $\mathrm{Li}^{6}$
}

Received: 14 December 2018 / Revised: 23 May 2019 / Accepted: 15 June 2019 / Published online: 9 August 2019

(c) The Author(s) 2019

\begin{abstract}
Artesunate (ART) is the derivative of artemisinin isolated from the traditional Chinese medicine qinghao. Although several studies reported the efficiency of artesunate in the treatment of malaria, inhibiting fibroblasts and collagen synthesis, the association between artesunate and scar formation is unclear. The research was designed to study the significance of artesunate (ART) on the expression of transforming growth factor (TGF- $\beta 1$ ) and small mother against decapentaplegic (SMAD3) in rabbit's ear hypertrophic scar model. Twenty-four New Zealand white rabbits were randomly divided into six groups: control group, matrix group, low-concentration artesunate group (0.48\%), medium-concentration artesunate group (0.96\%), highconcentration artesunate group (1.92\%) and silicone gel group. Punched defects were established on each rabbit's ear which resulted in a hypertrophic scar. On the 28th day, topical artesunate creams were applied twice a day except on the control group. On the 56th day, scar samples were collected for histopathology and immunoassay. Hematoxylin and eosin staining, Van Gieson staining, immunohistochemistry and Western blot analysis were done. Amongst the six groups, findings showed that the medium-concentration artesunate group $(0.92 \%)$ efficiently decreased hypertrophic scar formation and significantly reduced fibroblasts and collagen synthesis. The results had also shown a decrease in the expression of transforming growth factor (TGF- $\beta 1$ ) and declined small signal mother against decapentaplegic (Smad3). The overall study shows efficacy and mechanism of artesunate. It concluded that the medium concentration of artesunate $(0.92 \%)$ could be an effective therapeutic agent for hypertrophic scars.
\end{abstract}

Keywords Artesunate $\cdot$ Hypertrophic scar $\cdot$ SMAD3 - TGF- $\beta 1$

\begin{tabular}{|c|c|}
\hline \multicolumn{2}{|c|}{ Abbreviations } \\
\hline ART & Artesunate \\
\hline $\mathrm{AA}$ & Area density of collagen fibers \\
\hline CASK & $\begin{array}{l}\text { Calcium/calmodulin-dependent serine protein } \\
\text { kinase }\end{array}$ \\
\hline DAB & 3,3-Diaminobenzidine \\
\hline $\mathrm{HI}$ & Hypertrophic Index \\
\hline $\mathrm{H} \& \mathrm{E}$ & Hematoxylin-eosin staining \\
\hline ID1 & $\begin{array}{l}\text { Down-regulation of inhibitors of differentiation } \\
1\end{array}$ \\
\hline NA & $\begin{array}{l}\text { Numerical densities of fibroblasts on the area } \\
\text { (NA) }\end{array}$ \\
\hline OD & Optical density \\
\hline
\end{tabular}

Girju Rajbanshi and Ling Chen contributed equally to this work.

Xiaolin Nong

xnong@gxmu.edu.cn

Extended author information available on the last page of the article
PBS Phosphate buffer saline

SDS Sodium alkyl sulfate

SD Standard deviation

SMAD3 Small mother against decapentaplegic

TGF $\beta 1$ Transforming growth factor

VG Van Gieson

WB Western blot

\section{Introduction}

A hypertrophic scar is a clinical manifestation of malfunctioned wound healing process identified by an overabundance of collagen and extreme deposition of extracellular matrix which is caused by physical injury, inflammatory reactions and deep burn [8]. Hypertrophic scar results in the loss of tissue function and disfigurement [24, 29]. Currently, treatment of hypertrophic scar during an abnormal wound healing process has been a great challenge for 
medical practitioners [9]. Previously, many alternative therapeutic modalities such as avotermin, intralesional steroid injection, onion extract, and heparin gel application, silicone gel sheeting, bleomycin injection, and pulsed dye laser had been tested to treat hypertrophic scar occurrence. However, none could decrease or block this process, and no authentic treatment has been identified yet. Therefore, a reliable treatment procedure which provides painless, effective wound healing capacity and patient and physician friendly environment to alleviate hypertrophic scar needs to be discovered [13, 26].

Artesunate (ART) is the derivative of artemisinin isolated from the traditional Chinese medicine qinghao and has a favorable pharmacological profile with water solubility and high oral bioavailability $[1,28]$. It has been used clinically as anti-malarial agents for many years [20]. Furthermore, ART has been shown to possess antiviral, anti-inflammatory and anti-cancer effects $[9,10,16,19]$. The ART facilitates hypertrophic scar fibroblast cells to apoptosis in vitro by the change of cell cycle. It also suggested that intracellular calcium variation may be one of the mechanisms of hypertrophic scar fibroblast apoptosis induced by ART [14]. Another study also demonstrated that artesunate could induce the apoptosis of fibroblasts, inhibit TGF- $\beta 1$-induced epithelial-to-mesenchymal transition and downregulate the expression of TGF- $\beta 1$ in an animal model [36]. Additionally, the mechanism of ART inhibited the proliferation of fibroblast in keloid may be related to the up-regulation of calcium/calmodulin-dependent serine protein kinase (CASK) and down-regulation of inhibitors of differentiation 1(ID1) [31].

Transforming growth factor (TGF- $\beta 1$ ) is a significant signaling factor in wound healing process by regulating cell differentiation, collagen production and extracellular matrix degradation. The prolonged high expression of TGF- $\beta 1$ is accepted for the formation of hypertrophic scars. Inhibition of TGF- $\beta 1$ signaling pathway may express one of the effective strategies for limiting excessive scarring [2]. Additionally, TGF- $\beta$ initiates and terminates tissue repair, and its sustained production contributes to the development of fibrosis. It related to a wide variety of fibrotic diseases affecting many body organs including the liver, kidney, lung, and skin [18]. Recent research suggests that the TGF- $\beta /$ Smad signaling pathway closely related to a normal scar and hypertrophic scar formation. Moreover, a member of the Smad family mainly SMAD3 interposes collagen production in dermal fibroblasts stimulated by TGF- $\beta$. Increasing evidence has presented that blocking TGF- $\beta /$ Smad signaling pathway prohibits the development of hypertrophic scars [33]. This study was designed to analyze the efficiency of ART cream on hypertrophic scars in vivo, as well as elucidate the mechanism of action of ART, and explore the function of the transforming growth factor (TGF- $\beta 1$ )/small mother against decapentaplegic (Smad3) signaling pathway in hypertrophic scar formation.

\section{Materials and methods}

This experimental study was performed by following the guidelines for the use of laboratory animal subjects in research set by Animal Center of Guangxi Medical University and Hospital of Stomatology affiliated to Guangxi Medical University, license number: SCXK GUI (2009-0002).

\section{Preparation of drugs and chemicals}

\section{Preparation of paste for a matrix group}

The oil-soluble materials $2.4 \mathrm{~g}$ white petroleum, $1.6 \mathrm{~g}$ octadecanol, $0.4 \mathrm{~g}$ glycerol monostearate were heated in an electric constant-temperature water bath to evaporate the dish to $80{ }^{\circ} \mathrm{C}$. The water-soluble materials $0.2 \mathrm{~g}$ sodium lauryl sulfate, $1.4 \mathrm{~g}$ glycerin, $0.04 \mathrm{~g}$ ethyl $p$-hydroxybenzoate and distilled water were placed in another evaporating dish heated to $80^{\circ} \mathrm{C}$. The aqueous phase was slowly added to the oil phase at a temperature of $80{ }^{\circ} \mathrm{C} .20 \mathrm{~g}$ of matrix control pastes were prepared.

\section{Preparation of ART cream with different concentrations}

Artesunate purchased from Guilin Pharmaceutical Co. Ltd. (No. 43 Qilidian Road, Guilin, Guangxi, China 541004). According to the above method, $20 \mathrm{~g}$ of matrix control paste was added, and the corresponding weight of artesunate was made. $0.48 \%$ low artesunate drug concentration, $0.96 \%$ medium artesunate drug concentration, and $1.92 \%$ high artesunate drug concentration were prepared.

\section{Animal research and therapy}

Twenty-four New Zealand white rabbits, obtained from Guangxi Medical University animal experiment center in Nanning, China, with an initial body weight of $1.8-2.5 \mathrm{~kg}$, were used. All animals were kept under constant conditions (temperature $25 \pm 1{ }^{\circ} \mathrm{C}$ ) and had free access to a standard diet and drinking water. All animal treatments were strictly following the International Ethical Guidelines and the National Institutes of Health Guide concerning the Care and Use of Laboratory Animals, and the experiments were carried out with the approval of the Animal Experimentation Ethics Committee of Guangxi Medical University animal experiment center.

Rabbits were randomly distributed into six groups as follows: the control group, matrix group, and three ART groups in a dose-dependent manner $(0.48 \%$ low-concentration 
artesunate, $0.96 \%$ medium-concentration artesunate, $1.92 \%$ high-concentration artesunate), and silicone gel group, four rabbits in each group. Hypertrophic scars were induced on the ventral surface of rabbit ears. Briefly, the rabbits were anesthetized with the administration of $10 \%$ chloral hydrates $(3-4 \mathrm{ml} / \mathrm{kg}$ ) and then cycloid wounds $1 \mathrm{~cm}$ in diameter were created down to bare cartilage and dislodged the perichondrium on the rabbit's ear, six injuries in each ear (Fig. 1). Each wound was covered by iodophors. Then, after maintaining homeostasis, the wound was enclosed with an antiseptic bandage. The sterile dressing was removed at the end of the 3rd week. The scars of the matrix group were thinly applied with matrix paste cream twice a day; the three ART groups were applied the corresponding ointment with ART twice a day and silicone gel on silicone gel group from 4th week to the end of the 7th week. In the control group, no ointment was applied to rabbits. At the end of 7 th week, all animals were anesthetized and killed, and then each of the hypertrophic scars tissues was divided for further laboratory investigation as follows: $10 \%$ formaldehyde for histopathological examination, Van Gieson (VG), immunohistochemical analyses for TGF- $\beta 1$ and Smad3 protein expression, and Western blot analysis.

\section{H\&E and determination of Scar Elevation Index}

Scar tissues were embedded in paraffin and cut into 4- $\mu \mathrm{m}$ sections for $\mathrm{H} \& \mathrm{E}$ and Van Gieson (VG) staining. H\&E was staining performed. Briefly, the tissue sections were stained in hematoxylin dye, washed in running water, stained using eosin and finally mounted under coverslips. Then slides were studied using an ordinary optical microscope from Japan Olympus Corporation. The pathological features were observed and the degree of scar hyperplasia was expressed as SEI. SEI is defined as the ratio of the scar tissue height to the healthy tissue below the hypertrophic scar. Hypertrophy Index (HI), numerical densities of fibroblasts on the area (NA) and area density of collagen fibers (AA) were also analyzed.

\section{Van Gieson staining}

Van Gieson staining is the simplest method of differential staining of collagen and other connective tissue. Briefly, the tissue was dewaxed, rehydrated, stained in Verhoeff's solution for $1 \mathrm{~h}$, washed and then differentiated in $2 \%$ ferric chloride for $2 \mathrm{~min}$. Tissue should be completely black microscopically and then treated with $5 \%$ sodium thiosulfate for 1 min, washed and counterstained in Van Gieson's solution for 3-5 min. Finally, the tissue was dehydrated, cleared and sealed. The Image Pro plus 4.5 software evaluated collagen deposition.

\section{Immunohistochemical analysis}

Immunostaining techniques were performed using the scar tissue to demonstrate the presence of TGF- $\beta 1$ and SMAD3. The sections were placed on slides and deparaffinized for
Fig. 1 Preparation of hypertrophic scars on the ventral side of the rabbit's ear. Six wounds $1 \mathrm{~cm}$ in diameter were created on bare cartilage on the ventral surface of rabbit's ear using dermal punch biopsy defect
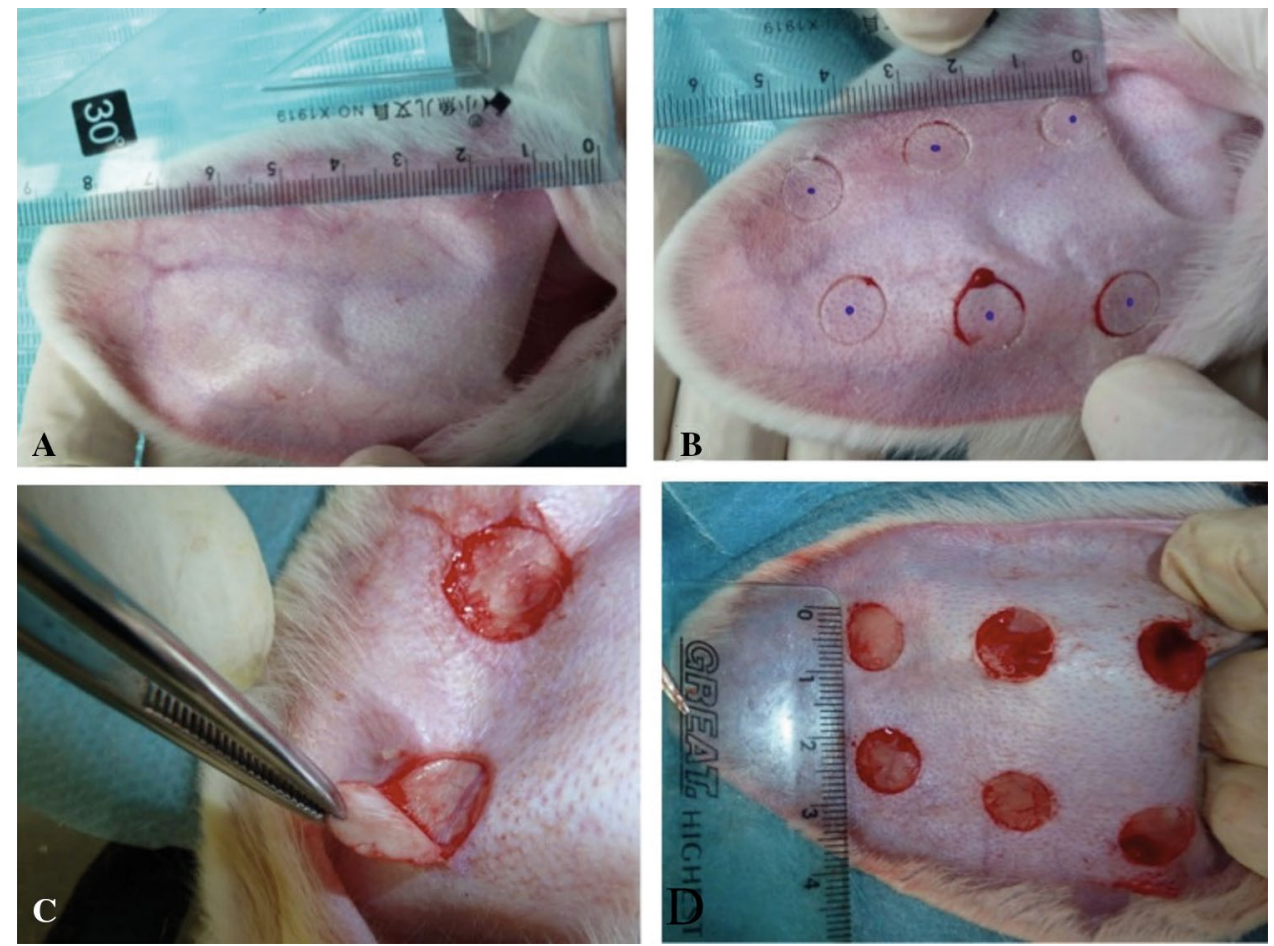
$5 \mathrm{~min}$. Each in the three-step xylene series rehydrated using a set of graded alcohol and distilled water. Heating was applied for $20 \mathrm{~min}$ o induce antigen retrieval in $10 \mathrm{mM}$ sodium citrate buffer, $\mathrm{pH}$ 6.0. Endogenous peroxide activity was quenched using $3 \%$ hydrogen peroxide in absolute methanol for $7 \mathrm{~min}$ at room temperature (RT). The tissue sections were rinsed thrice with PBS ( $\mathrm{pH}$ 7.4) for $5 \mathrm{~min}$ between each consecutive step. The parts were then incubated in blocking serum for $5 \mathrm{~min}$ to prevent nonspecific antibody binding. After that, the sections were incubated with a primary antibody for $60 \mathrm{~min}$ in a humidity chamber at RT. After treating the articles with biotin-labeled secondary antibody for $15 \mathrm{~min}$ and streptavidin-peroxidase enzyme for 15 min at RT, the color reaction was performed using aminoethyl carbazole (AEC) chromogen (ThermoFisher Scientific, USA) for 5-10 min. Sections were counterstained with Mayer's hematoxylin for 1-2 min and suspended in a waterbased mounting medium (ThermoFisher Scientific, USA). A double-blind method at high magnification $(400 \times)$ was used to get photographs of samples and stored in the computer, then Image Pro Plus (IPP) Version 6.0 professional image analysis software (Media Cybernetics, USA) was used.

\section{Western blot analyses}

The scar tissue was homogenized in cell lysis buffer for Western blot. The protein lysates were processed from cultured fibroblasts separated by 8 or $10 \%$ polyacrylamide gel, transmitted to a polyvinylidene difluoride membrane, and immunoblotted with primary antibodies at $4{ }^{\circ} \mathrm{C}$ overnight. The membranes were incubated with horseradish peroxidase-conjugated secondary antibodies. The primary antibodies used were mouse monoclonal anti-TGF- $\beta 1$ and mouse monoclonal anti-Smad3 obtained from Santa Cruz Biotechnology (Santa Cruz, Calif., USA) and mouse monoclonal glyceraldehyde 3-phosphate dehydrogenase (GAPDH) antibody obtained from Cell Signaling Technology (Beverly, Mass., USA). GAPDH protein was used as an internal control. Visualization of the detection system (Millipore) was followed by exposure to X-ray film. The protein bands were then analyzed by Image $\mathrm{J}$ software. The gray-scale values of detected proteins were normalized to the benefits of the corresponding GAPDH band to determine the expression change of the protein.

\section{Statistical analysis}

Statistical results were achieved by the SPSS software version 13.0 for Windows and data were given as means \pm standard deviation (SD). Comparison was by one-way ANOVA; $P<0.05$ was considered to be statistically significant for experimental and control groups.

\section{Results}

\section{Effect of ART cream on hypertrophic scars in rabbit's ear}

Three weeks after the operation, a raised and visible scar gradually initiated in a primary wound healing stage. At the end of the 7th week, appearance of representative wounds in each group was assessed (Fig. 2a), which displayed that hypertrophic scars from the control and matrix group were highly elevated from surrounding tissue, while injuries in the treatment groups were flatter than those in the control and matrix groups. There was a significant difference between the control group and treatment groups $(* * P<0.05)$ (Fig. 2b).

\section{H\&E and VG staining findings}

Hematoxylin-eosin staining showed dermis layer with ridges, angiogenesis and irregular fibroblasts in control group and matrix groups; however, this ameliorated in the ART treatment groups and silicone gel group (Fig. 3). Figure 4 shows typical rabbit ear scar sections stained with Van Gieson (VG) staining. The collagen fibers were denser, thicker and more disordered in control and matrix groups. Typical bundle-shaped collagen fibers appeared in the ART treatment group, especially in the mediumconcentration artesunate group, while there was a marked improvement in silicone gel groups with less density and arranged collagen fibers.

\section{Hypertrophic Index (HI), fibroblast number density (NA), and the surface density of collagen fibers (AA)}

Hypertrophic scar index, Fibroblast number density and surface density of collagen fibers were significant between control group, matrix group, and treatment groups, $\left({ }^{\#} P<0.05\right)$ ) and artesunate group (low concentration, medium concentration, high concentration) and silicone gel group showed statistical significance $(* * P<0.01)$ (Fig. 5a-c).

\section{Effect of ART on TGF- $\beta 1$ protein expression}

Figure $6 \mathrm{a}$ shows the expression of TGF- $\beta 1$ protein extracted from frozen rabbit ear tissue. The expression of TGF- $\beta 1$ protein in the control and matrix group markedly increased, while ART dose-dependent group and silicone gel group decreased. The treatment group and control group were statistically significant $\left({ }^{\#} P<0.01\right)$ and 
Fig. 2 a Macroscopic hypertrophic scar view on rabbit's ear observed on day 28 after medication. (A) Control group, (B) matrix group, (C) lowconcentration ART cream, (D) medium-concentration ART cream, (E) high-concentration ART cream, and (F) silicone gel group. Scar on mediumconcentration ART cream (D) and silicone gel groups (F) was smooth, and the color is close to normal. $\mathbf{b}$ Comparison of the scar thickness in the rabbit's ear scar samples. (A) control group, (B) matrix group, (C) low-concentration ART cream, (D) medium-concentration ART cream (E) high-concentration ART cream, and (F) silicone gel group. Error bars represent SD. A column represents mean $\pm \mathrm{SD}, n=4 * P<0.05$ compared with control group

Fig. 3 H\&E staining for histological analysis of hypertrophic scar on rabbit's ear. a Control group, b matrix group, c lowconcentration ART cream, $\mathbf{d}$ in medium-concentration ART cream, e high-concentration artesunate cream, and $\mathbf{f}$ silicone gel group. The scale bar on $\mathrm{H} \& \mathrm{E} 50 \mu \mathrm{m}$ a
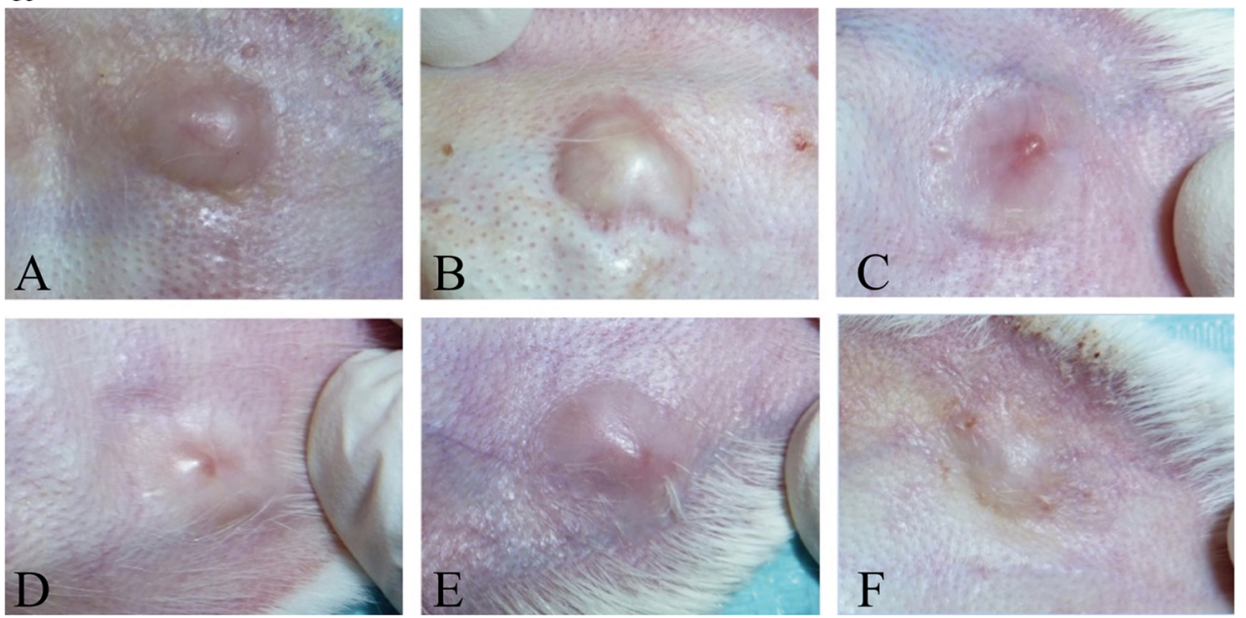

b

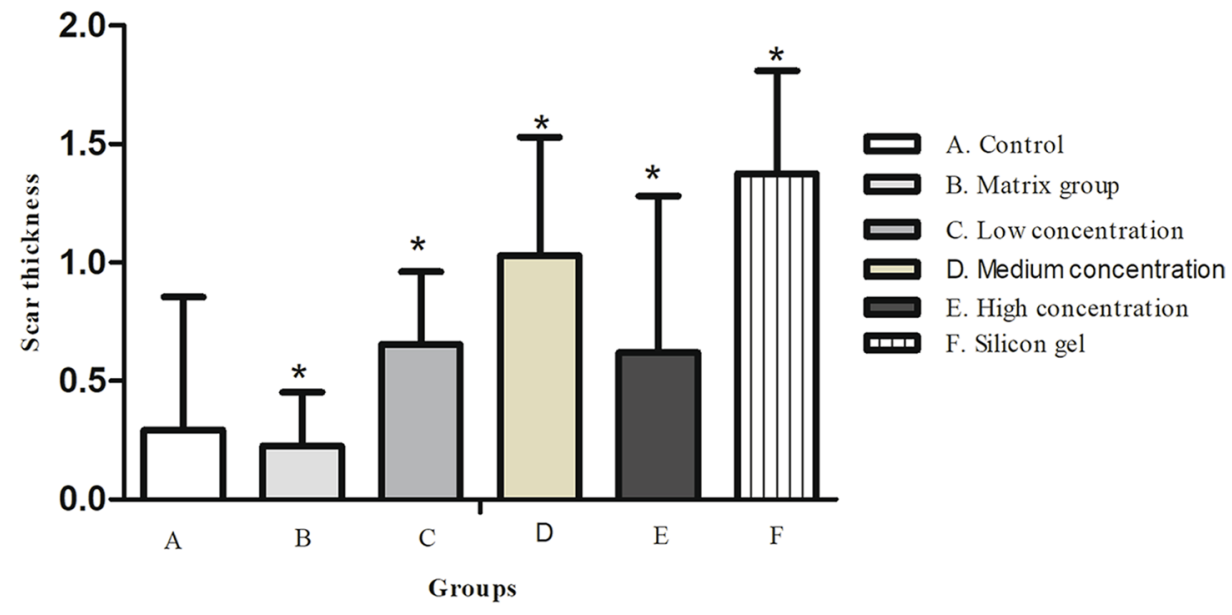

Comparing Scar thickness
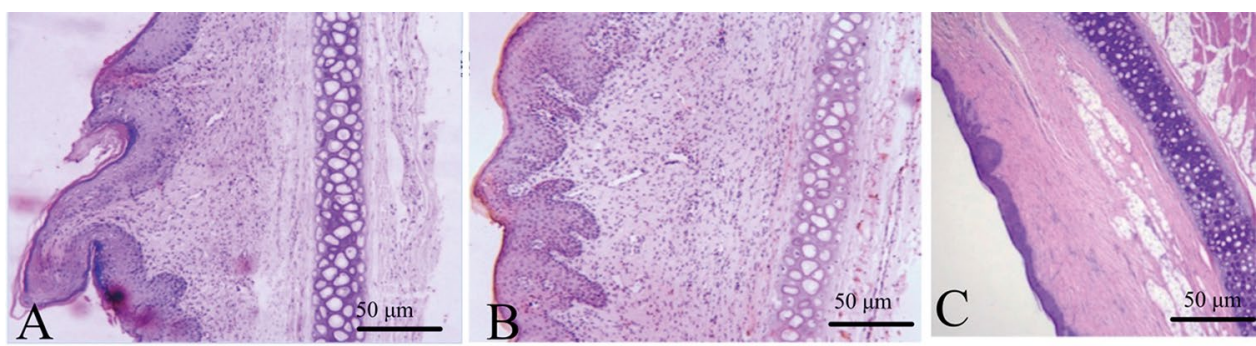

D
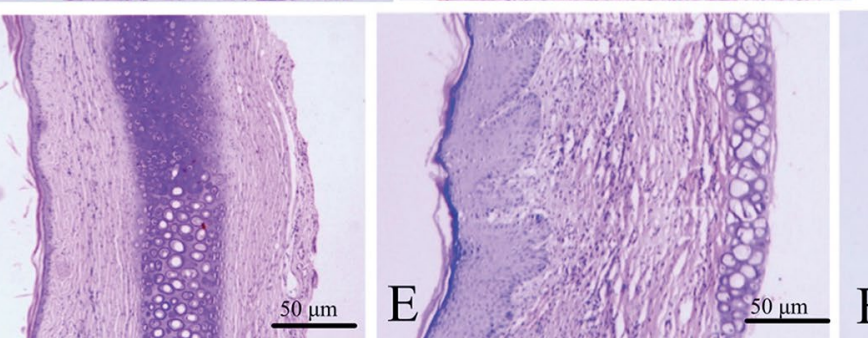
Fig. 4 Van Gieson (VG) staining for collagen fibers on hypertrophic scar of rabbit's ear. a Control group, $\mathbf{b}$ matrix group, c low-concentration ART cream, $\mathbf{d}$ medium-concentration ART cream, e high-concentration ART cream, and $\mathbf{f}$ silicone gel group. Scale bar $20 \mu \mathrm{m}$
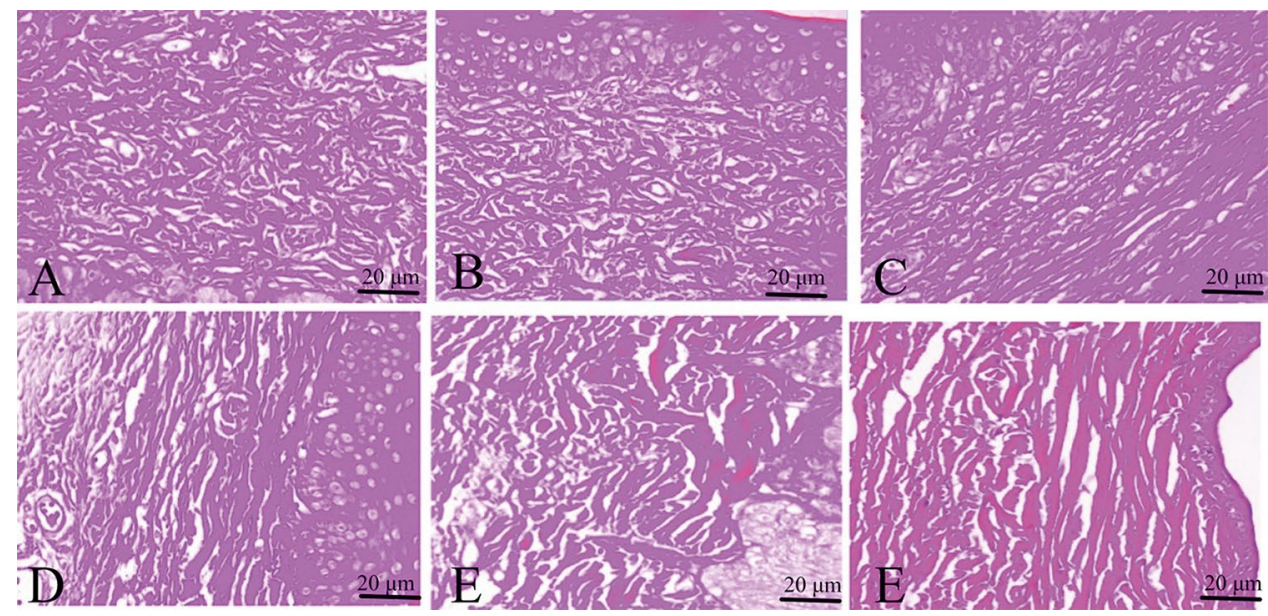

artesunate treatment group and silicone gel group were also statistical significant $(* * P<0.01)$ (Fig. 6b).

\section{Effect of ART on SMAD 3 protein expression}

Figure 7a shows the expression of SMAD3 protein extracted from frozen rabbit ear tissue. The expression of SMAD3 protein in the control and matrix groups markedly increased, while decreased in the ART dose-dependent group and silicone gel group. The treatment group and control group were statistically significant $\left({ }^{\#} P<0.01\right)$ and artesunate treatment group and silicone gel group were also statistically significant $(* * P<0.01)$ (Fig. 7b).

\section{Western blot detection of TGF- $\beta 1$ protein expression and SMAD 3 protein expression}

Figure 8a shows TGF- $\beta 1$ expression was suppressed in the medium-concentration ART group and silicone gel group when compared to that of the control group. The western blot detection of TGF- $\beta 1$ protein expression showed a statistical difference between control and treatment groups $(* * P<0.01)$, Fig. 8b. Figure 9a shows SMAD3 expression was suppressed in the medium-concentration ART group and silicone gel group when compared to that of the control group. The Western blot detection of SMAD3 protein expression showed a statistical difference between control and treatment groups $(* * P<0.01)$, Fig. 9 b.

\section{Discussion}

Inflammation, granulation, and tissue formation are physiological processes of normal wound healing which occur in sequence. Abnormal reaction in the wound healing process can lead to fibroblast replication with overabundant production of collagen and excessive contraction, resulting in hypertrophic scar (HS) formation [40]. Fibroblasts isolated from HS tissue have been shown to have an increased expression of TGF- $\beta 1$ and TGF- $\beta$ R as compared to those from healthy skin and are thought to play a vital role in HS formation [39]. Treatment of HS is typically challenging due to the limited understanding of its pathogenesis [37]. Current therapies for HS include intralesional steroid therapy, pulsed-dye laser ablation, or combining the use of surgery with the above therapies. However, such therapeutic strategies are not satisfactory because they are time consuming or expensive; therefore, the development of novel hypertrophic scar treatments is necessary [38].

Pre-clinical animal models are of great importance for studying the development of hypertrophic scars and evaluating the therapeutic effects of anti-scar treatment. Several models of hypertrophic scarring are reported. The most frequently used hypertrophic scar model is the rabbit ear excisional wound model [4]. In the present study, we successfully established an animal model of hypertrophic scars on rabbit ears by incision wounding, in which each wound ensured removal of full-thickness skin and perichondrium.

Artesunate is a stable derivative of artemisinin which has been declared as antitumor activity in cancer cells and reportedly explains the induction of apoptosis through reactive oxygen species (ROS) generation, angiogenesis inhibitor effect, and inhibition of hypoxia-inducible factor- $1 \alpha$ (HIF-1 $\alpha)$ by ROS generation [5, 27]. Interestingly, artesunate with a double oxygen bridge structure was discovered as a potential ferroptosis inducer. The study verified that artemisinin derivatives induced irondependent cell death (ferroptosis) in tumor cells [22]. Additionally, artesunate targeted the activation of hepatic stellate cell ferroptosis and its effect was associated with the activation of ferritinophagy. At the same time, these findings will provide further mechanisms for understanding the protective effect of artesunate against $\mathrm{CCl}_{4}$-induced liver fibrosis [15], the retarded proliferation of lung 
Fig. 5 a Hypertrophic Index (HI) on rabbit's ear scar samples. In (A) control group, (B) matrix group, (C) lowconcentration ART cream, (D) medium-concentration ART cream, (E) high-concentration ART cream, and $(\mathrm{F})$ silicone gel group. Error bars represent SD. A column represents mean $\pm \mathrm{SD}, n=4 * * P<0.01$ compared with artesunate treatment group and silicone gel group, ${ }^{\#} P<0.05$ compared with the control group. b Fibroblast number density (NA) on the hypertrophic scar on the rabbit's ear. (A) Control group, (B) matrix group, (C) low-concentration ART cream, (D) medium-concentration ART cream, (E) high-concentration ART cream, and (F) Silicone gel group. Error bars represent SD. A column represents mean $\pm \mathrm{SD}, n=4 * * P<0.01$ compared with ART treatment group and silicone gel group, ${ }^{\#} P<0.01$ compared with the control group. c Surface area of collagen fibers (AA) on the hypertrophic scar on the rabbit's ear. (A) Control group, (B) matrix group, (C) lowconcentration ART cream, (D) medium-concentration ART cream, (E) high-concentration ART cream, and (F) silicone gel group. Error bars represent SD. A column represents mean $\pm \mathrm{SD}, n=4 * * P<0.01$ compared with A\&M treatment group, ${ }^{\#} P<0.01$ compared with control group

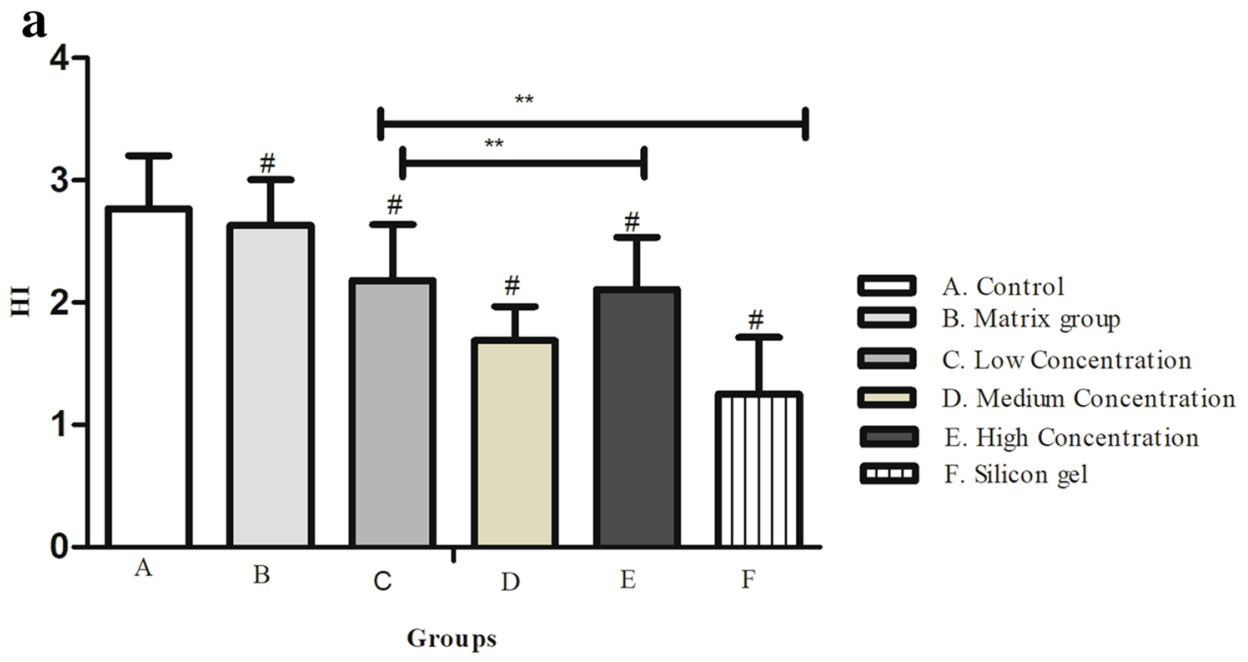

Effect of Hypertrophic In dex (HI)

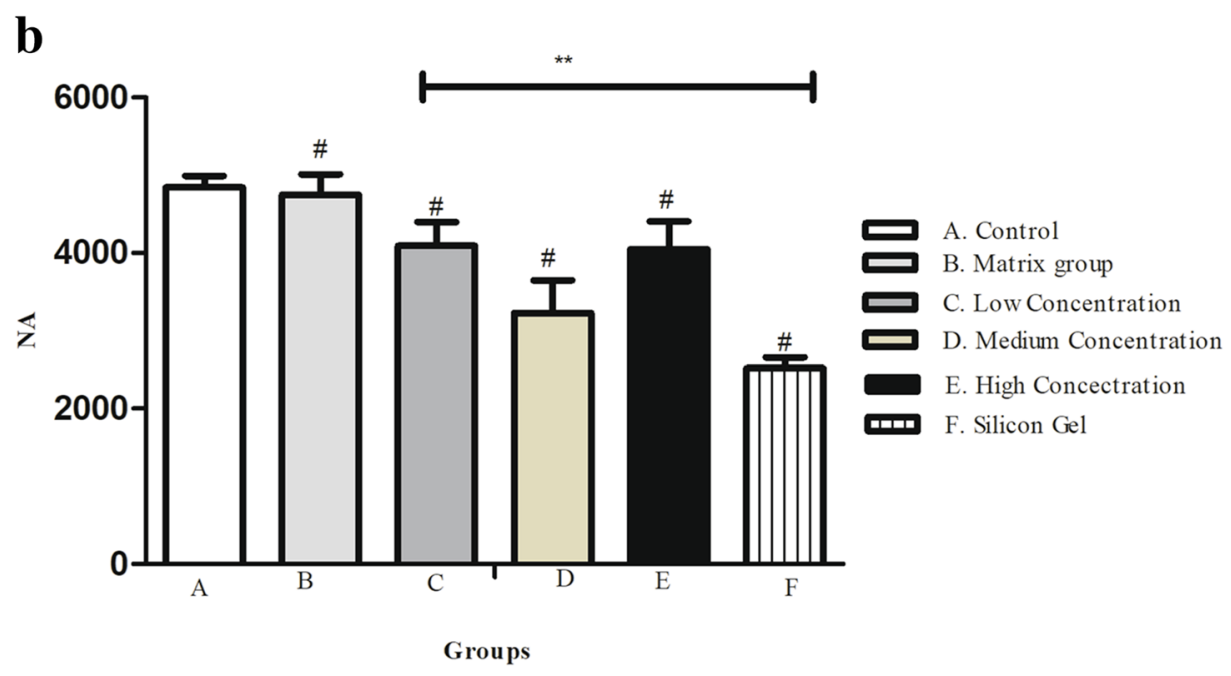

c Effect of Fibroblast numerical density (NA)

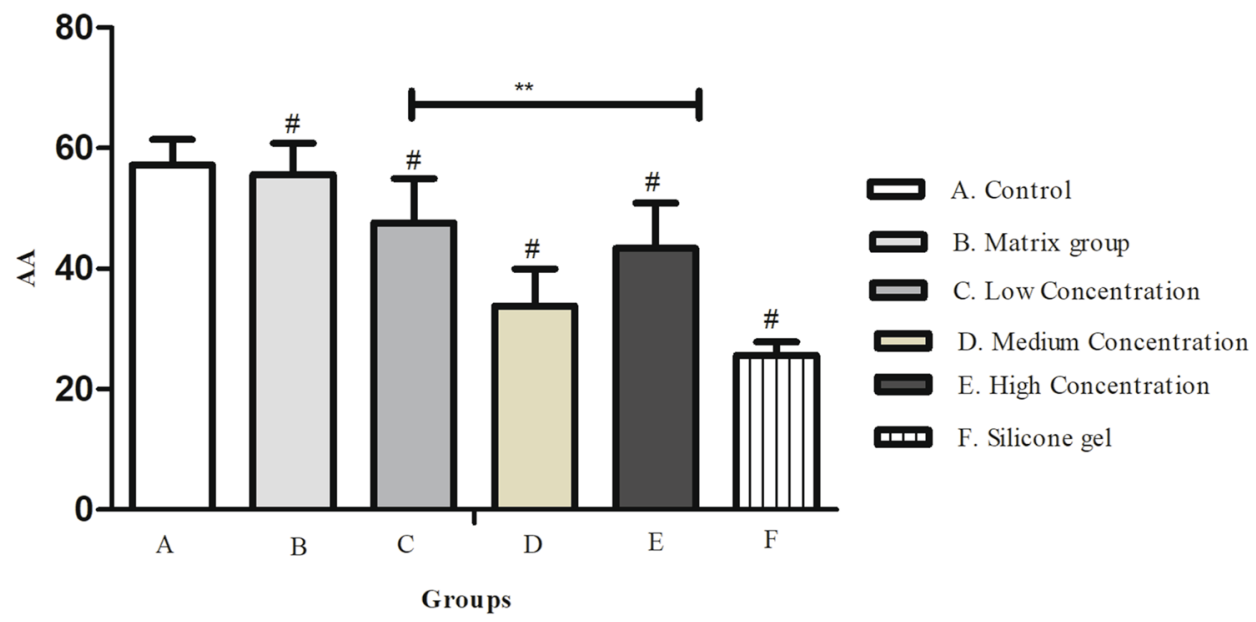

Effect of area density on the area (AA) 
Fig. 6 a Immunohistochemical findings on TGF- $\beta 1$ protein expression on rabbit hypertrophic scars for fibroblast on dermis layer. (A) Control group, (B) matrix group, (C) low-concentration ART cream, (D) medium-concentration ART cream, (E) high-concentration ART cream, and (F) silicone gel group. DAB, scale bar, $20 \mu \mathrm{m}$. b Effect of TGF- $\beta 1$ protein expression on the hypertrophic scar on rabbit's ear. (A) Control group, (B) matrix group, (C) low-concentration ART cream, (D) medium-concentration ART cream, (E) high-concentration ART cream, and (F) silicone gel group. Error bars represent SD. A column represents mean $\pm \mathrm{SD}, n=4 * * P<0.01$ compared with artesunate treatment group, ${ }^{\#} P<0.01$ compared with the control group $\mathbf{a}$

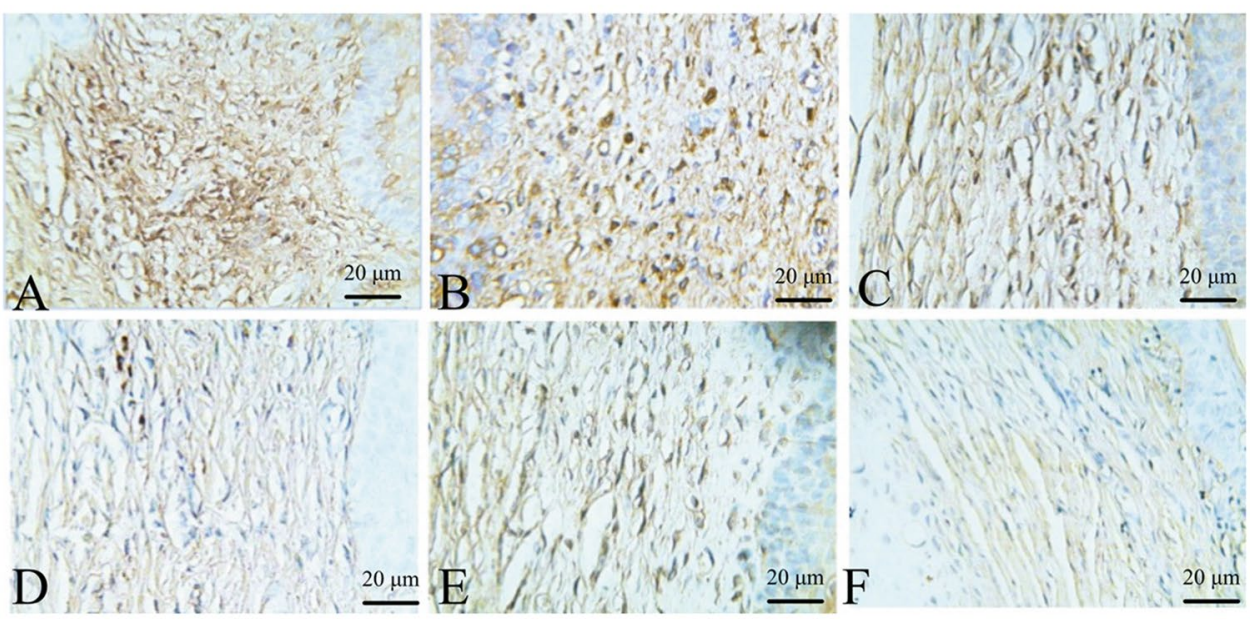

b

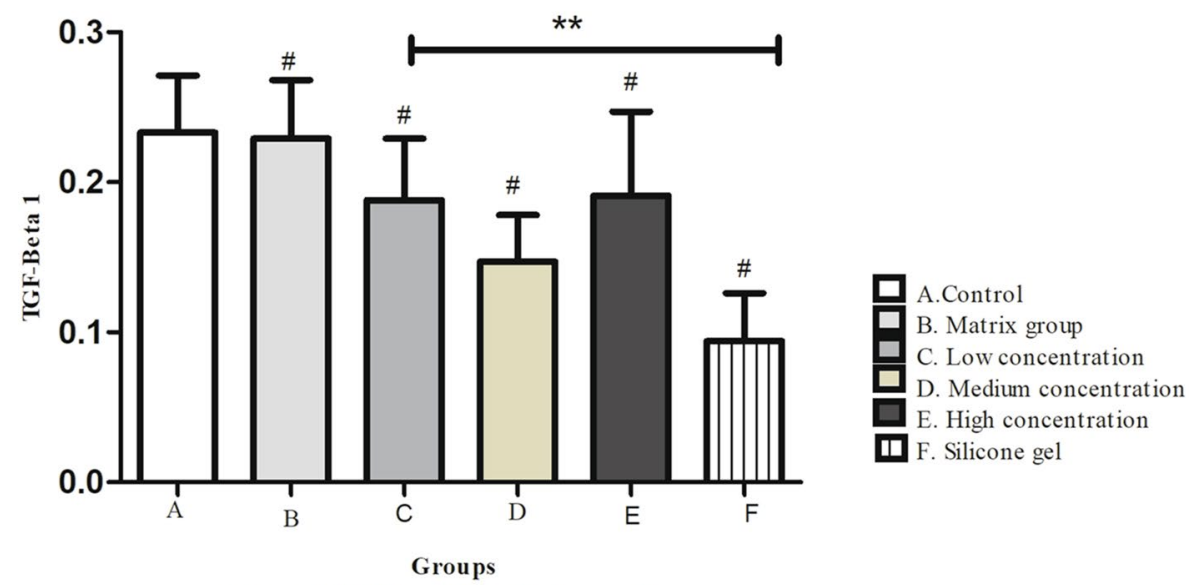

Effect of TGF-beta1 Protein Expression

fibrosis, immunological hepatic fibrosis and induced apoptosis of hepatic stellate cells [3, 37]. Another study displayed that artemisinin derivative dihydroartemisinin specifically caused head and neck cancer cell death through contributing ferroptosis and apoptosis [17]. It reported that ART could decrease the expression of related extracellular matrix proteins and exert an inhibitory effect on cell proliferation [14]. Because of its unique characteristics, ART was recently used to treat proliferative fibrosis diseases, and satisfactory results had been achieved [5]. All these studies prompt ART may play a role in fibrous hyperplastic disease. In the present study, the histopathological assessment showed that ART significantly ameliorated fibroblast/keratinocyte in the dermis. Subsequently, ART decreases Hypertrophic Index, fibroblast number density (NA) and the surface density of collagen fibers in a dosedependent manner, and thus inhibits fibroblast proliferation, collagen deposition, and scar hyperplasia.
TGF- $\beta 1$ is a type of cytokine with many biological effects. When tissue is damaged after injury, TGF- $\beta 1$ is released from inflammatory cells which stimulates fibroblast proliferation, collagen synthesis, deposition and remodeling of ECM [11]. The hypertrophic scar tissue and hypertrophicderived fibroblast produced more mRNA, protein for TGF$\beta 1$ and prolonged expression of the TGF- $\beta$ receptors than normal skin or fibroblasts derived from normal skin which suggests a possible role for TGF- $\beta 1$ in hypertrophic scar formation Thus, it can be seen that TGF- $\beta 1$ has an essential part in serving as a link between injury and fibrosis [7]. It is found that ART could inhibit fibroblast proliferation and reduce epidural fibrosis formation [30]. In the present study, the expression of TGF- $\beta 1$ was significantly increased in scar tissues, while overexpression of ART could inhibit TGF- $\beta 1$ expression. Smad signaling transduction proteins act as an intracellular mediator of TGF- $\beta$ signaling which are the only downstream substrates of TGF- $\beta$ receptors (T $\beta R$ ) 
Fig. 7 a Immunohistochemical findings on SMAD3 protein expression on rabbit hypertrophic scars for fibroblast on dermis layer. (A) Control group, (B) matrix group, (C) low-concentration ART cream, (D) medium-concentration ART cream, (E) high-concentration ART cream, and (F) silicone gel group. DAB, scale bar, $20 \mu \mathrm{m}$. b Effect of SMAD3 protein expression on the hypertrophic scar on rabbit's ear. (A) Control group, (B) matrix group, (C) low-concentration ART cream, (D) medium-concentration ART cream, (E) high-concentration ART cream, and (F) silicone gel group. Error bars represent SD. A column represents mean $\pm \mathrm{SD}, n=4 * * P<0.01$ compared with artesunate treatment group, ${ }^{\#} P<0.01$ compared with the control group
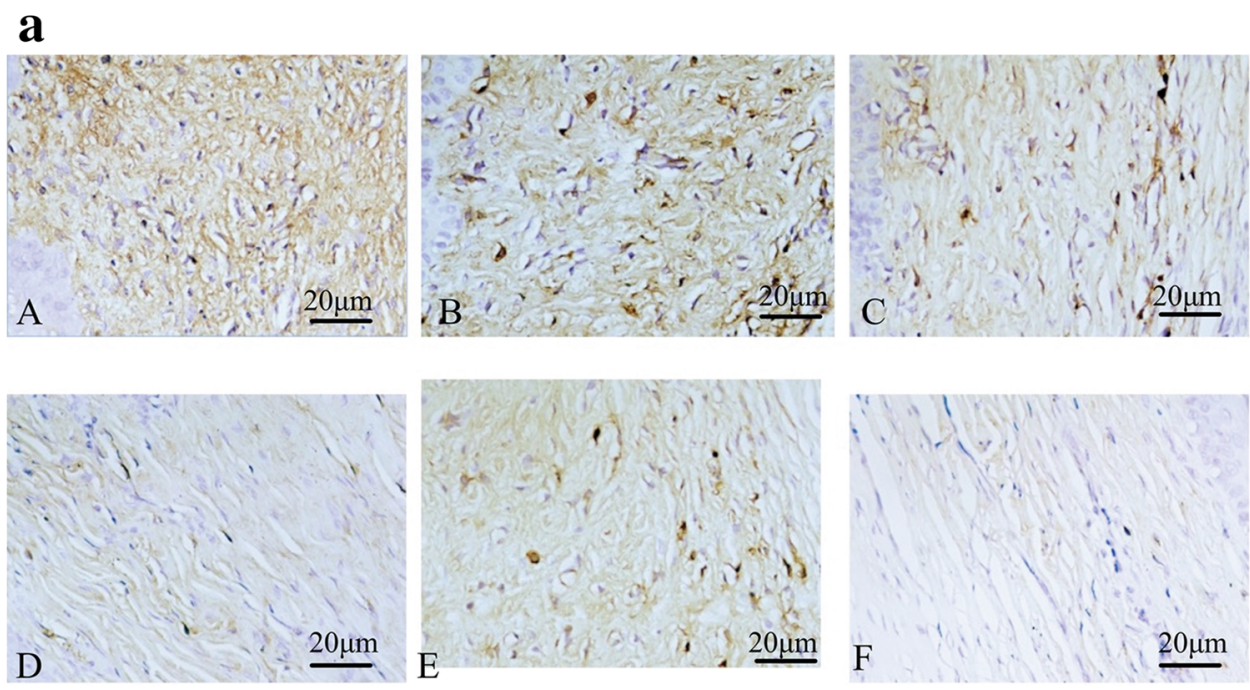

b

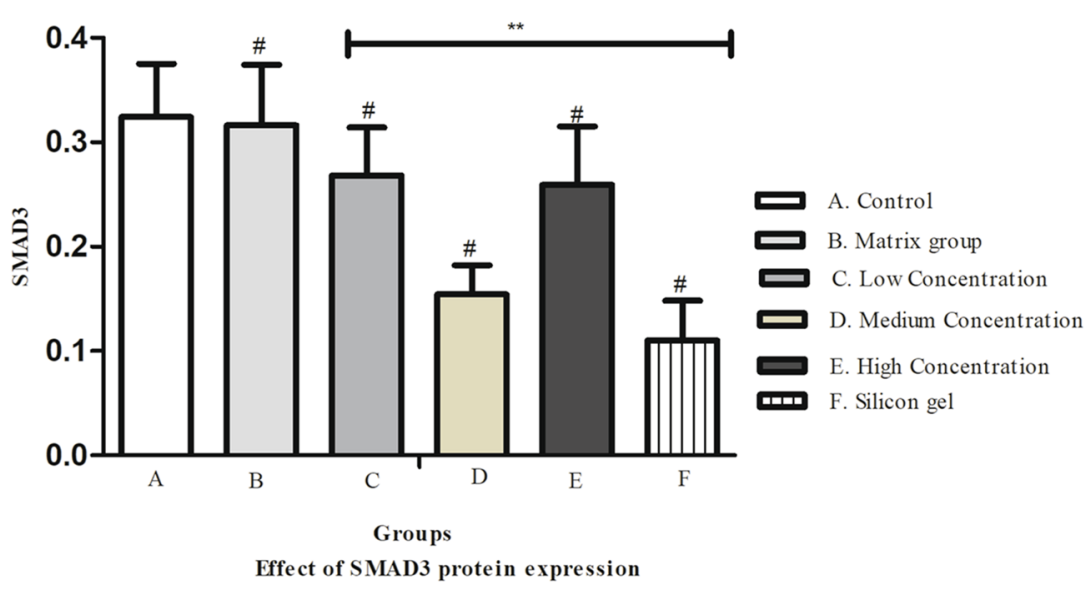

[23]. TGF- $\beta 1$ may promote the phosphorylation of Smad2 and Smad3 and have a stimulating effect on fibrosis process. Current research suggests that TGF- $\beta / S m a d$ signaling plays a significant role in the pathogenesis of scars. Silencing the Smad 2 or Smad3 genes could decrease the collagen synthesis and inhibit fibroblast proliferation [21]. Thus, TGF-/ Smad signaling is recognized as a therapeutic target for the treatment of scars. Our study demonstrated that the overexpression of ART significantly inhibited the phosphorylation of Smad2 and Smad3, which is realized by suppressing TGF- $\beta 1$ expression pathway.

With much research on the mechanisms of scar formation in recent years, many different compounds used TGF- $\beta /$ SMAD3 as cytokines for the process of hypertrophic scar. TRAP-1-like protein (TLP) is a novel human cytoplasmic protein found associated with the TGF- $\beta /$ Smad signaling transduction pathway. Besides, it has a significant role such as the ability to regulate $\mathrm{Smad} 2 / 3$ in opposite directions simultaneously. Overexpression of TLP suppresses the expression of the Smad3/4-specific receptor protein
(SBE) induced by TGF- $\beta$ [32]. The study has proved that the mechanism by which pearl powder promotes wound healing is partly due to its ability to stimulate fibroblast mitosis, collagen deposition, and TIMP-1 production [14]. Some preclinical studies have shown that LY2109761 is a TGF- $\beta$ receptor I (II) kinase inhibitor which is useful as an anticancer compound so medical practitioners have great concern [34]. Subsequently, it reported that LY2109761 attenuated radiation-induced pulmonary murine fibrosis [7]. Our results showed that ART did not cause cell death in HSF cells but moderately decreased the TGF- $\beta 1 / \mathrm{SMAD} 3$-induced cell proliferation at a medium concentration of ART and silicone gel compared to other concentrations of ART. Further study showed that ART on immunohistochemistry and Western blot analysis significantly inhibits TGF- $\beta 1 /$ SMAD3-induced collagen production in HSF cells in a dose-dependent manner and increased expression in control and matrix groups.

In summary, this study provides evidence that overexpression of ART promotes wound healing, alleviates path morphology change in scar tissues, and reduces ECM 
Fig. 8 a Effects of ART cream on TGF- $\beta 1$ protein expression analyzed by Western blot using anti-TGF- $\beta 1$ and anti-GAPDH antibodies. The intensities of TGF- $\beta 1$ bands normalized to GAPDH of the corresponding treatment groups. (A) Control group, (B) matrix group, (C) low-concentration ART cream, (D) medium-concentration ART cream, (E) high-concentration ART cream, and (F) silicone gel group. b Western blot expressing TGF- $\beta 1$ on the hypertrophic scar on rabbit's ear. (A) Control group, (B) matrix group (C) low-concentration ART cream, (D) medium-concentration ART cream, (E) high-concentration ART cream, and (F) silicone gel group. Error bars represent SD. A column represents mean $\pm \mathrm{SD}, n=4 * * P<0.01$ compared with ART treatment group, ${ }^{\#} P<0.01$ compared with control group $\mathbf{a}$
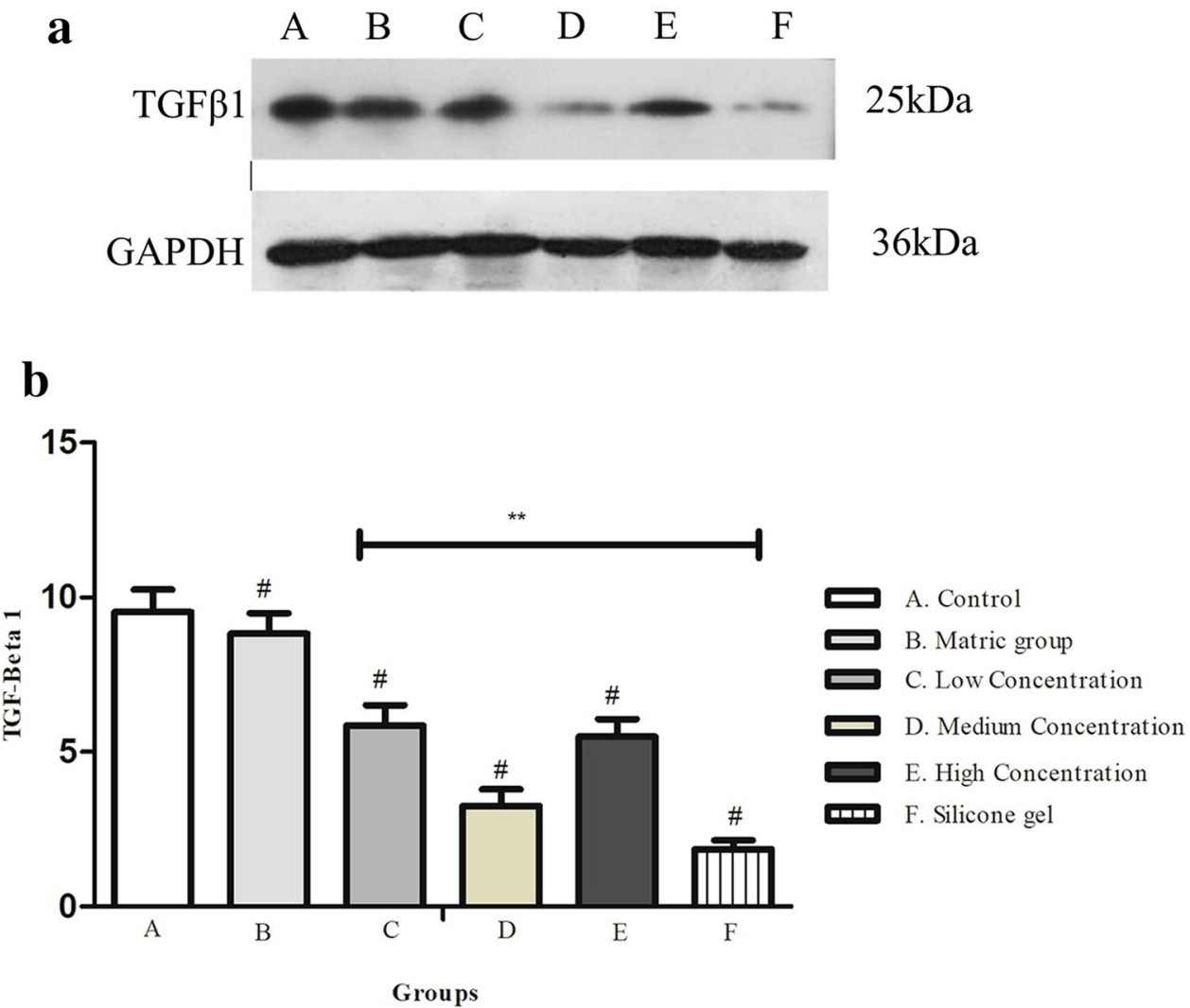

Expressing TGF-beta 1 by Western blot
Fig. 9 a Effects of ART cream on $\mathrm{Smad} 3$ protein expression analyzed by Western blot using anti-Smad3 and anti-GAPDH antibodies. The intensities of Smad3 bands normalized to GAPDH of the corresponding treatment groups. (A) Control group, (B) matrix group, (C) low-concentration ART cream, (D) medium-concentration ART cream, (E) high-concentration ART cream, and (F) silicone gel group. b Western blot expressing SMAD3 on the hypertrophic scar on rabbit's ear. (A) Control group, (B) matrix group, (C) low-concentration ART cream, (D) medium-concentration ART cream, (E) high-concentration ART cream, and (F) silicone gel group. Error bars represent SD. A column represents mean $\pm \mathrm{SD}, n=4 * * P<0.01$ compared with ART treatment group, ${ }^{\#} P<0.01$ compared with the control group

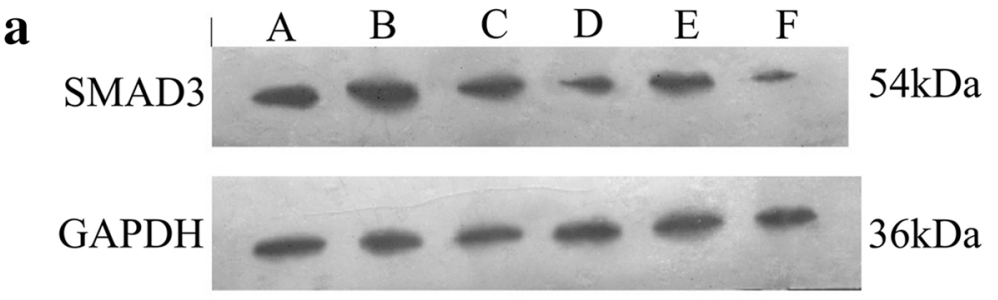

b

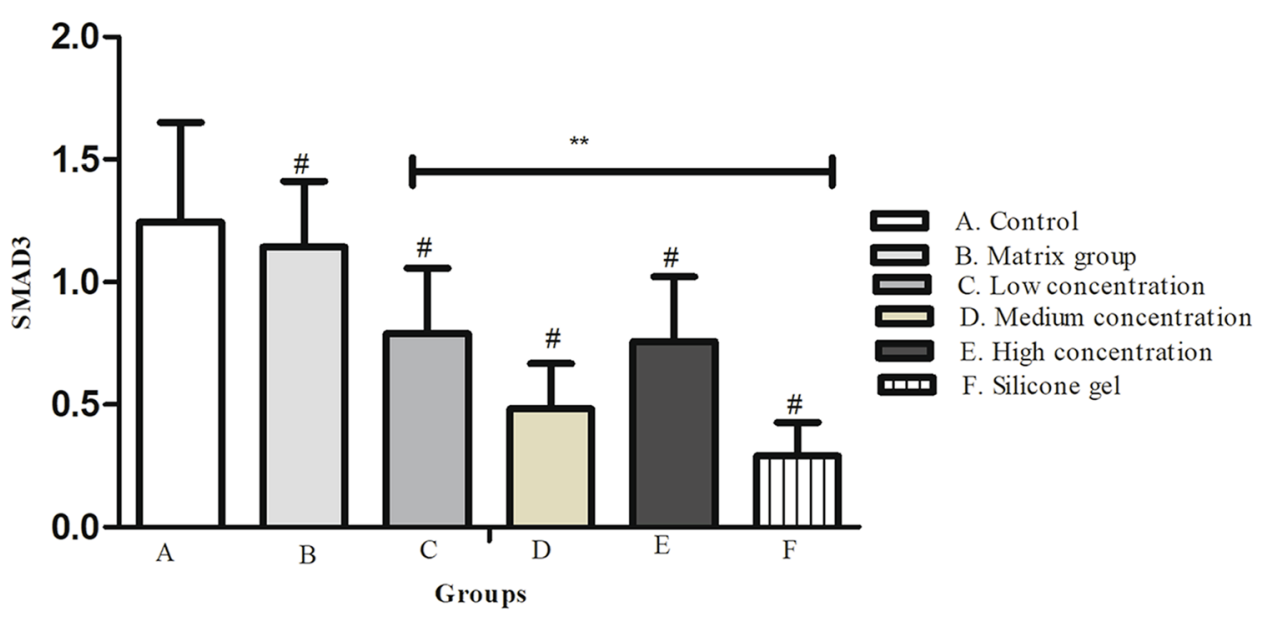

Expressing SMAD 3 by Western Blot 
production by inhibiting the TGF- $\beta / \mathrm{Smad} 3$ signaling pathway in the scaled model of a rabbit. This study also revealed that ART in a dose-dependent manner decreased TGF- $\beta 1$-/SMAD3-induced proliferation of fibroblasts and collagen production, and attenuated the TGF- $\beta 1$-/SMAD3induced contraction of gels containing HSFs. Our results suggest that ART may be a novel therapeutic strategy for hypertrophic scars. Future studies are required to determine other potential mechanisms to develop further and improve the efficacy of ART therapy in the clinical management of hypertrophic scars.

Funding This study financially supported by The National Natural Science Foundation Project (no. 81060156), Guangxi Special Key Subjects of Science and Technology of Traditional Chinese Medicine (GZK-10-010), and the Guangxi Natural Science Foundation (no. 0447033).

\section{Compliance with ethical standards}

Conflict of interest The authors have no potential conflicts of interest.

Ethical approval This experimental study was performed following the guidelines for the use of laboratory animal subjects in research set by Animal Center of Guangxi Medical University and Hospital of Stomatological affiliated to Guangxi Medical University, license number: SCXK GUI (2009-0002).

Open Access This article is distributed under the terms of the Creative Commons Attribution 4.0 International License (http://creativeco mmons.org/licenses/by/4.0/), which permits unrestricted use, distribution, and reproduction in any medium, provided you give appropriate credit to the original author(s) and the source, provide a link to the Creative Commons license, and indicate if changes were made.

\section{References}

1. Berte N, Lokan S, Eich M, Kim E, Kaina B (2016) Artesunate enhances the therapeutic response of glioma cells to temozolomide by inhibition of homologous recombination and senescence. Oncotarget 7(41):67235-67250. https://doi.org/10.18632/oncot arget. 11972

2. Boye A, Wu C, Jiang Y, Wang J, Wu J, Yang X et al (2015) Compound Astragalus and Salvia miltiorrhiza extracts modulate MAPK-regulated TGF-beta/Smad signaling in hepatocellular carcinoma by the multi-target mechanism. J Ethnopharmacol 169:219-228. https://doi.org/10.1016/j.jep.2015.04.013

3. Cao J, Wang W, Li Y et al (2016) Artesunate attenuates unilateral ureteral obstruction-induced renal fibrosis by regulating the expressions of bone 24 morphogenetic protein-7 and uterine sensitization-associated gene-1 in rats. Int Urol Nephrol 48:619-629

4. DomergueS Jorgensen C, Noël D (2015) Advances in research in animal models of burn-related hypertrophic scarring. J Burn Care Res 36:259-266. https://doi.org/10.1097/bcr.0000000000000167

5. Du Y, Li LN, Fang BW (2015) Effects of artesunate on hepatic fibrosis and its mechanism. Zhongguo Ying Yong Sheng Li Xue Za Zhi 31(1):14-17
6. Efferth T (2017) From ancient herb to the modern drug: Artemisia аппи a and artemisinin for cancer therapy. Semin Cancer Biol 46:65-83. https://doi.org/10.1016/j.semcancer.2017.02.009

7. Flechsig P, Dadrich M, Bickelhaupt S et al (2012) LY2109761 attenuates radiation-induced pulmonary murine fibrosis via reversal of TGF-beta and BMP-associated proinflammatory and proangiogenic signals. Clin Cancer Res 18(13):3616-3627

8. Gauglitz GG (2013) Management of keloids and hypertrophic scars: current and emerging options. Clin Cosmet Investig Dermatol 6:103-114. https://doi.org/10.2147/CCID.S35252

9. Guo J, Lin Q, Shao Y, Rong L, Zhang D (2017) miR-29b promotes skin wound healing and reduces excessive scar formation by inhibition of the TGF-beta1/Smad/CTGF signaling pathway. Can J Physiol Pharmacol 95(4):437-442. https://doi. org/10.1139/cjpp-2016-0248

10. He RR, Zhou HJ (2008) Progress in research on the anti-tumor effect of artesunate. Chin J Integr Med 14(4):312-316. https:// doi.org/10.1007/s11655-008-0312-0

11. Henderson J, Ferguson MW, Terenghi G (2012) The reinnervation pattern of wounds and scars after treatment with transforming growth factor beta isoforms. J Plast Reconstr Aesthet Surg 65(4):e80-e86

12. Jian-Ping D, Jun C, Yu-Fei B, Bang-Xing H, Shang-Bin G, Li-Li J (2010) Effects of pearl powder extract and its fractions on fibroblast function relevant to wound repair. Pharm Biol 48(2):122-127

13. Khetarpal S, Kaw U, Dover JS, Arndt KA (2017) Laser advances in the treatment of burn and traumatic scars. Semin Cutan Med Surg 36(4):185-191. https://doi.org/10.12788/j.sder.2017.030

14. Kong H, Yu Q, Zhu L (2007) Experimental study on artesunate inducing apoptosis of hypertrophic scar fibroblasts. Zhongguo Xiu Fu Chong Jian Wai Ke Za Zhi 21(9):970-974

15. Kong Z, Liu R, Cheng Y (2019) Artesunate alleviates liver fibrosis by regulating ferroptosis signaling pathway. Biomed Pharmacother 109:2043-2053. https://doi.org/10.1016/j.biopha.2018.11.030

16. Konstat-Korzenny E, Ascencio-Aragon JA, Niezen-Lugo S, Vazquez-Lopez R (2018) Artemisinin and its synthetic derivatives as a possible therapy for cancer. Med Sci (Basel) 6(1):89. https://doi.org/10.3390/medsci6010019

17. Lin R, Zhang Z, Zhou P Chen Y, Zou C, Feng, et al (2016) Dihydroartemisinin (DHA) induces ferroptosis and causes cell cycle arrest in head and neck carcinoma cells. Cancer Lett 381:165-175

18. Liu Y, Huang G, Mo B, Wang C (2017) Artesunate ameliorates lung fibrosis via inhibiting the Notch signaling pathway. Exp Ther Med 14:561-566

19. Lee SH, Cho YC, Kim KH, Lee IS, Choi HJ, Kang BY (2015) Artesunate inhibits proliferation of naïve CD4(+) T cells but enhances function of effector T cells. Arch Pharm Res 38(6):1195-1203. https://doi.org/10.1007/s12272-014-0491-5

20. Miranda AS, Brant F, Rocha NP, Cisalpino D et al (2013) Further evidence for an anti-inflammatory role of artesunate in experimental cerebral malaria. Malar J 12:388. https://doi. org/10.1186/1475-2875-12-388

21. Nicklas D, Saiz L (2013) Computational modeling of Smadmediated negative feedback and crosstalk in the TGF-beta superfamily network. J R Soc Interface 10(86):20130363. https://doi. org/10.1098/rsif.2013.0363

22. Ooko E, Saeed ME, Kadioglu O, Sarvi S, Colak M, Elmasaoudi $\mathrm{K}$ et al (2015) Artemisinin derivatives induce iron-dependent cell death (ferroptosis) in tumor cells. Phytomedicine 22:1045-1054

23. Phan TT, Lim IJ, Chan SY et al (2004) Suppression of transforming growth factor beta/Smad signaling in keloid-derived fibroblasts by quercetin: implications for the treatment of excessive scars. J Trauma 57(5):1032-1037

24. Rabello FB, Souza CD, Farina Junior JA (2014) Update on hypertrophic scar treatment. Clinics (Sao Paulo) 69:565-573 
25. Ren XF, Mu LP, Jiang YS et al (2015) LY2109761 inhibits metastasis and enhances chemosensitivity in osteosarcoma MG-63 cells. Eur Rev Med Pharmacol Sci 19(7):1182-1190

26. Sari E, Bakar B, Dincel GC, Budak Yildiran FA (2017) Effects of DMSO on a rabbit ear hypertrophic scar model: a controlled randomized experimental study. J Plast Reconstr Aesthet Surg 70(4):509-517. https://doi.org/10.1016/j.bjps.2017.01.006

27. Tsuda K, Miyamoto L, Hamano S, Morimoto Y, Kangawa Y, Fukue C et al (2018) Mechanisms of the $\mathrm{pH}$ - and oxygendependent oxidation activities of artesunate. Biol Pharm Bull 41(4):555-563. https://doi.org/10.1248/bpb.b17-00855

28. Tu Y (2011) The discovery of artemisinin (qinghaosu) and gifts from Chinese medicine. Nat Med 17(10):1217-1220. https://doi. org/10.1038/nm.2471

29. Uzun H, Bitik O, Hekimoglu R, Atilla P, Kayikcioglu AU (2013) Angiotensin-converting enzyme inhibitor enalapril reduces the formation of hypertrophic scars in a rabbit ear wounding model. Plast Reconstr Surg 132(3):361e-e371. https://doi.org/10.1111/ j.1524-475X.2007.00226.X

30. Wan Q, Chen H, Li X, Yan L, Sun Y, Wang J (2019) Artesunate inhibits fibroblasts proliferation and reduces surgery-induced epidural fibrosis via the autophagy-mediated p53/p21waf1/cip1 pathway. Eur J Pharmacol 842:197-207. https://doi.org/10.1016/j. ejphar.2018.10.048

31. Wang CM, Chen J, Jiang M, Xuan XP (2014) Li HX (2014) Relationship between artesunate influence on the process of TGFbeta1 induced alveolar epithelial cells transform into mesenchymal cells and on idiopathic pulmonary fibrosis. Yao Xue Xue Bao 49:142-147 (in Chinese)

32. Wang X, Qian Y, Jin R, Wo Y et al (2013) Effects of TRAP-1like protein (TLP) gene on collagen synthesis induced by TGFbeta/Smad signaling in human dermal fibroblasts. PLoS One 8(2):e55899. https://doi.org/10.1371/journal.pone.0055899

33. Wang YW, Liou NH, Cherng JH, Chang SJ et al (2014) siRNAtargeting transforming growth factor-beta type I receptor reduces wound scarring and extracellular matrix deposition of scar tissue. J Investig Dermatol 134(7):2016-2025. https://doi.org/10.1038/ jid.2014.84

34. Wei G, Xu Q, Liu L, Zhang H et al (2018) LY2109761 reduces TGF- $\beta 1$-induced collagen production and contraction in hypertrophic scar fibroblasts. Arch Dermatol Res 310(8):615-623. https ://doi.org/10.1007/s00403-018-1849-1

35. Wu X, Bian D, Dou Y, Gong Z et al (2017) Asiaticoside hinders the invasive growth of keloid fibroblasts through inhibition of the GDF-9/MAPK/Smad pathway. J Biochem Mol Toxicol 31(8):89. https://doi.org/10.1002/jbt.21922

36. Xiao L, He GZ, Yu ZH, Tang XQ, Ren YH (2013) Expressions of the related genes in fibroblasts of human keloid and the effect of artesunate. Zhonghua Shao Shang Za Zhi 29(2):185-190

37. Zeng AH, Ou YY, Guo MM, Dai X, Zhou DZ, Chen R (2015) Human embryonic lung fibroblasts treated with artesunate exhibit reduced rates of proliferation and human cytomegalovirus infection in vitro. J Thorac Dis 7(7):1151-1157. https://doi. org/10.3978/j.issn.2072-1439.2015.07.05

38. Zhao JC, Zhang BR, Shi K, Wang J, Yu QH, Yu JA (2018) Lower energy radial shock wave therapy improves characteristics of hypertrophic scar in a rabbit ear model. Exp Ther Med 15(1):933939. https://doi.org/10.3892/etm.2017.5441

39. Zhang J, Li Y, Bai X, Li Y, Shi J, Hu D (2018) Recent advances in hypertrophic scar. Histol Histopathol 33:27-39

40. Zhu Z, Ding J, Tredget EE (2016) The molecular basis of hypertrophic scars. Burns Trauma 4:2. https://doi.org/10.1186/s4103 8-015-0026-4

Publisher's Note Springer Nature remains neutral with regard to jurisdictional claims in published maps and institutional affiliations.

\section{Affiliations}

\section{Xiaolin Nong ${ }^{1}(1) \cdot$ Girju Rajbanshi ${ }^{1,2} \cdot$ Ling Chen $^{1} \cdot$ Jiaquan $\mathrm{Li}^{3} \cdot$ Zhan Li $^{1} \cdot$ Taotao Liu $^{4} \cdot$ Shihai Chen $^{5} \cdot$ Gao Wei $^{6}$. Jushang $\mathrm{Li}^{6}$}

Girju Rajbanshi

girjurajbanshi1@yahoo.com

\author{
Ling Chen \\ 30847588@qq.com
}

Jiaquan Li

1085026949@qq.com

Zhan Li

598846353@qq.com

Taotao Liu

liutaotao@gxmu.edu.com

Shihai Chen

haishi003@163.com

Gao Wei

weigao126@126.com

Jushang Li

drjushangli@163.com

1 Department of Oral and Maxillofacial Surgery, College and Hospital of Stomatology, Guangxi Medical University,
5-715, No. 10 Shuangyong Road, Nanning 530021, Guangxi, China

2 Department of Pediatrics Dentistry and Preventive Dentistry, College and Hospital of Stomatology, Guangxi Medical University, No. 10 Shuangyong Road, Nanning 530021, Guangxi, China

3 Medical Science Research Center, Guangxi Medical University, No. 22 Shuangyong Road, Nanning 530021, Guangxi, China

4 Department of Pharmacy, The First Affiliated Hospital of Guangxi Medical University, No. 6 Shuangyong Road, Nanning 530021, Guangxi, China

5 Department of Cosmetics and Plastic Surgery, The First Affiliated Hospital of Guangxi Medical University, No. 6 Shuangyong Road, Nanning 530021, Guangxi, China

6 Department of Dermatology, The First Affiliated Hospital, Guangxi Medical University, No. 6 Shuangyong Road, Nanning 530021, Guangxi, China 